\title{
Adapting educational experiences for the chemists of tomorrow
}

\author{
Mik Fanguy, Sang Yup Lee® and David G. Churchill
}

Technical universities are constantly experimenting with innovative student-centred classroom approaches. We describe flipped and linked classroom approaches in the context of our ongoing chemical education theme of catalysis.

The calling to teach the next generation of chemists in East Asia has led us and others to search for new modes of learning that can inspire creativity and self-reliance. Fresh experiences in learning arise from experiments in teaching. If we are not careful, from a student's perspective, the result might be trials and tribulations. Creativity in (chemistry) education comes down to different approaches. These forays, some linguistic in nature, could be anything from broad campus-wide initiatives to grassroots efforts. Grand initiatives require heavy cooperation, 'branding' and looking to the future - in brief, they require campus management. At technical universities, where developments in science and technology are often prioritized over new educational paradigms, individual professors and educational professionals alike seek to test their ability to create the classroom of the future.

\section{A case study in flipped classroom learning}

Regarding campus-wide efforts, about 10 years ago, Korea Advanced Institute of Science and Technology (KAIST) launched an educational platform called Education 3.0. In this flipped format of learning ${ }^{1}$, students watch pre-recorded online videos at home and then attend weekly face-to-face meetings. Here, they convene at round tables, prepare and deliver presentations, and participate in team-based discussion and learning on themes prescribed by a professor as per the syllabus. Under '3.0', learners performed projects, tasks and experiments together in a more embracing and interactive mode than was typically possible in traditional large lecture halls, exemplifying a marked difference from the then status quo. Unsurprisingly, because of this substantial change in classroom style, both professors and students at first found frustration. Amidst the faculty lunch dialogue, a pervasive joke emerged: "you can lecture any way you want, except by lecturing".

In response to these frustrations, a new 'one-stop shopping' approach was implemented across the campus, offering a tremendous array of alternatives deviating from the heavy reliance on video instruction of a flipped format course. Instead, fresh course plans were devoid of lectures and full of student interaction and collaboration through semester-long project-based and/or problem-based learning (Education 4.0). This widespread experience of online and blended instruction across the curriculum also facilitated remote learning, allowing the quality of KAIST instruction to be largely unaffected by the COVID-19 pandemic ${ }^{2}$.

\section{Chemistry education}

Amidst campus-wide initiatives, relying on great numbers of faculty marching to a proposed administrative drumbeat, there are subtler grassroots efforts to develop education methods that are sometimes esoteric but often more specific to a certain field of study.

A substantial amount of the coursework at any technical university involves chemistry in one form or another, such that it lives up to its place as the 'central science'. In addition, because professors have to get the point across, every such instructor, student and teaching assistant alike is faced with issues relevant to chemistry education whether they know it or not. Faculty members have been active in publishing articles covering topics from aspects of laboratory environment ${ }^{3}$, chemical safety and general chemistry ${ }^{4}$, as well as inter-language resources to help bring about new modes of learning ${ }^{5,6}$.

New dimensions of chemistry education and related training are being tested all the time. For example, the need to produce clear and compelling prose is important in securing research funding and getting papers accepted. To this end, we have been running a publishing club through which professors can share insights and tricks of the trade with students when submitting and responding to reviewer feedback. In addition, manuscript writing and presentation courses were invigorated by taking into account that linguistic challenges are coupled with scientific ones. The English as a Foreign Language Department at KAIST now provides discipline-specific Scientific Writing and Scientific Presentation courses for graduate students to afford them deep insights into the features that distinguish the dissemination of chemistry from that of other subjects.

\section{Catalysis as an example}

Research in scientific education and pedagogy allows us to explore how technology can enhance the classroom and how we abstract and visualize chemical concepts. As an example, an international project aims to put a spin on how we teach catalysis and create iconography for catalysts and the field of catalysis. One way to understand catalysis is to understand what ruins an otherwise happily working catalyst. Poisons and inhibitors can begin to shut down catalytic cycles that normally occur smoothly, whether it be in a catalytic converter, an enzyme in our body or an $n$th generation catalyst for industry. New ways to represent catalysts can be deeply explored from a hybrid education-science perspective.

Faculty members who teach science and engineering courses and those who teach communications courses can collaborate, often in globalized ways, to leverage technologyenhanced learning to increase instructional depth and discipline specificity in the instruction of scientific communication. Catalysis coverage can be deep yet tailored. Information and communication technologies

\section{Cf technology can enhance} the classroom and how we abstract and visualize chemical concepts 


\section{IN THE CLASSROOM}

can afford students access to a greater array of learning content to suit their individual needs, particularly with regard to the instruction of scientific communication. At KAIST, as in many global universities, students have varying levels of experience and skill with their research, with visual and verbal communication in their field, and with the English language in general. The ongoing research described here aims to teach the concept of inhibitors in an overlapping manner between content classes and communications classes; these can be linked by prior cooperation of instructors working in different departments. We hope that our approach will enable students to achieve an enriched understanding of inhibitors and their effects on chemical reactions, as students aim to express, both textually and visually in communication classes, these concepts to be understood by their peers first and a wider audience second.

Developing a new set of icons for catalysis is a long-term project. With computer-generated graphical chemistry representations and creative journal cover artwork appearing daily, as well as new representations of ligands, students can start by first identifying which previous artwork and pictorial renditions they find clearest and most helpful in conveying the necessary message.

\section{1 and beyond}

Ultimately, we are trying to optimize the educational experience in the era following COVID-19. More than ever, students are involved in student-centred hybrid learning. To alleviate students going vacuously from classroom to classroom, brilliant educational ideas coupled with course content can help retain long-term knowledge for one's life and scientific or business career. Beauty is often in the eye of the beholder in empowering student and professor initiatives alike.

Mik Fanguy', Sang Yup Lee $\mathbb{D}^{2 \otimes}$ and David G. Churchill ${ }^{3 凶}$

'English as a Foreign Language Department, Korea Advanced Institute of Science and Technology, Daejeon, Republic of Korea.

${ }^{2}$ Department of Chemical and Biomolecular Engineering, Korea Advanced Institute of Science and Technology, Daejeon, Republic of Korea.
${ }^{3}$ Department of Chemistry, Korea Advanced Institute of Science and Technology, Daejeon, Republic of Korea. 凶e-mail: leesy@kaist.ac.kr; dchurchill@kaist.ac.kr

https://oi.org/10.1038/s41570-021-00258-5

1. Casselman, M. D. et al. Dissecting the flipped classroom: using a randomized controlled trial experiment to determine when student learning occurs. J. Chem. Educ. 97, 27-35 (2020).

2. Lee, K., Fanguy, M., Lu, X. S. \& Bligh, B. Student learning during COVID-19: it was not as bad as we feared. Dist. Educ. https://doi.org/10.1080/ 01587919.2020.1869529 (2021)

3. Kim, T. T., Kim, H. \& Han, S. Academic research inspired design of an expository organic chemistry lab course. J. Kor. Chem. Soc. 62, 99-105 (2018).

4. Churchill, D. G. Chemical structure and accidental explosion risk in the research laboratory. J. Chem. Educ. 83, 1798-1803 (2006).

5. Churchill, D. G. Word reduction editing in secondlanguage scientific writing by east Asian and South Asian chemistry graduate students. J. Chem. Educ. 83, 1022-1023 (2006).

6. Chang, J. \& Churchill, D. Bringing out the "main characters" in general chemistry: can creating a sense of narrative in the classroom and for the textbook aid long-term memory? J. Chem. Educ. 88, 408-414 (2011).

Acknowledgements

M.F., S.Y.L. and D.G.C. acknowledge KAIST for research support and their undergraduate and graduate students for inspiration.

Competing interests

The authors declare no competing interests. 